\title{
The asthma-COPD overlap syndrome: do we really need another syndrome in the already complex matrix of airway disease?
}

This article was published in the following Dove Press journal:

International Journal of COPD

16 June 2016

Number of times this article has been viewed

\author{
Konstantinos Kostikas \\ Andreas Clemens \\ Francesco Patalano \\ Novartis Pharma AG, Basel, \\ Switzerland
}

Correspondence: Konstantinos Kostikas Novartis Pharma AG, Novartis Campus, 4002, Basel, Switzerland

$\mathrm{Tel}+4 \mid$ | 6 I 324593 |

Email kostas.kostikas@novartis.com
Abstract: The term asthma-COPD overlap syndrome (ACOS) is one of multiple terms used to describe patients with characteristics of both COPD and asthma, representing $\sim 20 \%$ of patients with obstructive airway diseases. The recognition of both sets of morbidities in patients is important to guide practical treatment decisions. It is widely recognized that patients with COPD and coexisting asthma present with a higher disease burden, despite the conceptual expectation that the "reversible" or "treatable" component of asthma would allow for more effective management and better outcomes. However, subcategorization into terms such as ACOS is complicated by the vast spectrum of heterogeneity that is encapsulated by asthma and COPD, resulting in different clinical clusters. In this review, we discuss the possibility that these different clusters are suboptimally described by the umbrella term "ACOS", as this additional categorization may lead to clinical confusion and potential inappropriate use of resources. We suggest that a more clinically relevant approach would be to recognize the extreme variability and the numerous phenotypes encompassed within obstructive airway diseases, with various degrees of overlapping in individual patients. In addition, we discuss some of the evidence to be considered when making practical decisions on the treatment of patients with overlapping characteristics between COPD and asthma, as well as the potential options for phenotype and biomarker-driven management of airway disease with the aim of providing more personalized treatment for patients. Finally, we highlight the need for more evidence in patients with overlapping disease characteristics and to facilitate better characterization of potential treatment responders.

Keywords: emphysema, chronic bronchitis, COPD, asthma, ACOS, overlap syndrome

\section{Introduction}

The term asthma-COPD overlap syndrome (ACOS) is used to describe patients who were presented with features of both asthma and COPD. ${ }^{1}$ Terms such as ACOS have arisen to further simplify the classification of patients with COPD and asthma into phenotypes that better describe an individual patient's disease characteristics; however, a balance must be sought between simplifying terminology versus considering the multiple clusters within the aforementioned diseases as distinct disease entities..$^{2,3}$ A more clinically relevant approach would be to recognize the extreme variability and the numerous phenotypes encompassed within obstructive airway disease, with various degrees of overlap in individual patients, and to create an awareness that "recognizes" this variability rather than creating an umbrella term, such as ACOS, to "simplify" it. Indeed, oversimplified terminology may result in unnecessary confusion for patients and health-care providers. 
Recognition of the considerable variability that exists within obstructive airway diseases is important, because patients with overlapping asthma and COPD are known to experience more frequent exacerbations, poorer quality of life, usually a more rapid decline in lung function, and higher morbidity and mortality than those with either COPD or asthma alone, ${ }^{1,4,5}$ not unlike what is observed with other comorbidities. As a result, the burden and cost, both direct and indirect, are greater in patients with overlapping asthma and COPD compared with those with either disease individually, with one estimate suggesting that the cost of overlapping asthma and COPD is double than that of asthma alone. ${ }^{6}$ Increasing awareness within the medical community of the heightened disease burden associated with overlapping morbidities is important and is clearly distinguishable from attempts to redefine patients under umbrella terms such as ACOS.

In this study, we review the current opinion on the identification and treatment of patients with overlapping characteristics of asthma and COPD and provide our commentary on whether there is a real clinical need for another "syndrome" and subcategorization of patients in the already complex environment of airways disease. To achieve this goal, we searched PubMed for relevant citations using search terms, including COPD, asthma, overlap, coexisting, and ACOS.

\section{Epidemiology}

Reliable epidemiological data relating to overlapping asthma and COPD are scarce, partly due to a historical insistence on a clear separation between COPD and asthma and partly due to clinical trial exclusion criteria, which have excluded patients with COPD from asthma trials and vice versa. ${ }^{78}$ The use of spirometric measures, such as forced expiratory volume in 1 second $\left(\mathrm{FEV}_{1}\right), \mathrm{FEV}_{1}$ /forced vital capacity ratio, and degree of reversibility, do not clearly differentiate between asthma and COPD, and may, in addition, contribute to the significant discrepancies that exist in the reported prevalence of overlapping asthma and COPD. ${ }^{9}$ The Global Initiative for Asthma/ Global initiative for chronic Obstructive Lung Disease (GINA/GOLD) guidelines cite epidemiological studies reporting different prevalence rates for overlapping asthma and COPD, with variation by sex and age, which is likely to reflect various sampling methods and definitions used..$^{1,10}$ The prevalence of overlapping asthma and COPD consistently increases with age, in a similar pattern with the increased prevalence of COPD. ${ }^{8,11,12}$ In a two-stage multicenter study, in the general population $(n=\sim 3,000)$, the prevalence of overlapping asthma and COPD was $1.6 \%, 2.1 \%$, and $4.5 \%$ in the

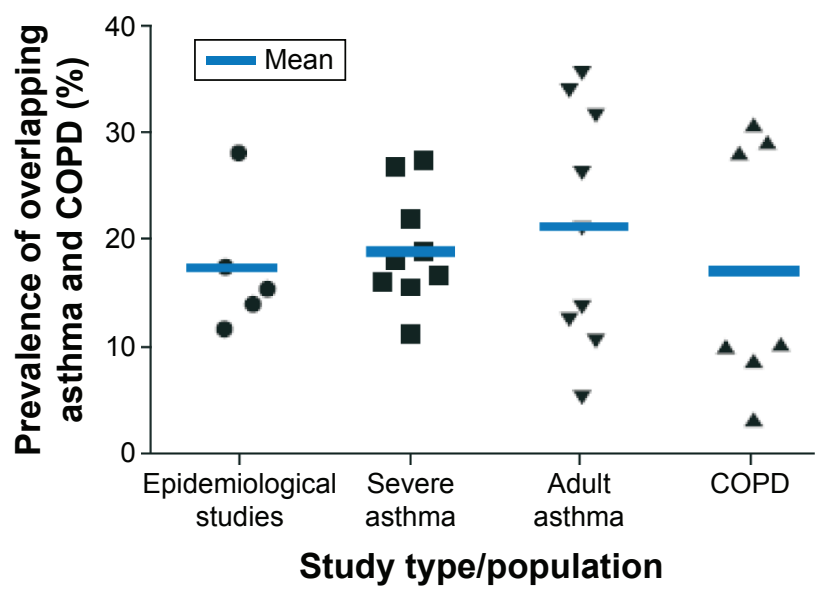

Figure I Prevalence of overlapping asthma and COPD in studies of varying designs in a cluster analysis (following a systematic literature search).

Notes: A systematic literature review of cluster analyses of asthma and COPD was performed. Articles from 2009 to September I, 20 I4, dealing with prevalence, morbidity, and treatment of asthma-COPD overlap, were identified and reviewed. The prevalence of overlapping asthma and COPD was reported in epidemiological studies $(\bullet)$, studies in severe asthma $(\bullet)$, studies in adult asthma $(\boldsymbol{\nabla})$, and studies in COPD ( $(\boldsymbol{\Delta})$. Reproduced from Thorax, Gibson PG, McDonald VM. 70(7), 683-69I. Copyright 2015. With permission from BMJ Publishing Group Ltd. ${ }^{10}$

age groups of 20-44 years, $45-64$ years, and $65-84$ years, respectively. ${ }^{8}$ In a more pragmatic approach, Gibson and McDonald ${ }^{10}$ have reported a prevalence of overlapping asthma and COPD of $\sim 20 \%$ in patients with obstructive airway diseases in the majority of analyses when various study designs were used (Figure 1).

\section{Definitions of obstructive airway disease}

Numerous definitions are proposed for distinct airway diseases, including asthma and COPD ${ }^{13}$ however, in reality many patients fit the criteria for more than one definition. ${ }^{13}$ The most recent GINA/GOLD guidelines define ACOS as being characterized by persistent airflow limitation with several features usually associated with asthma and several features usually associated with COPD ${ }^{14,15}$ however, the guidelines state that it is currently not possible to develop a more specific definition, due to the lack of evidence in relation to the underlying disease mechanisms. ${ }^{1}$ Guideline development in COPD has placed emphasis on recognizing COPD as a disease where incomplete reversibility of airflow obstruction is the defining characteristic; while for asthma, the emphasis is traditionally based on reversible airway obstruction. ${ }^{1,15}$ However, these definitions are limited, as not all patients fit "comfortably" within such clear-cut criteria. Indeed, it is recognized that besides patients with COPD, patients with asthma (particularly severe asthma) or overlapping asthma and COPD may also present with fixed 
airway obstruction. ${ }^{1,16,17}$ While there is an obvious need for clinical clustering under the well-established asthma and COPD definitions, there is also a requirement to recognize the variability that exists within these definitions, including varying levels of overlap between the two diseases.

For the airway disease clusters identified to date, limited evidence has linked pathological features with clinical patterns or treatment responses. ${ }^{1}$ The value of novel definitions and clustering should be considered alongside clinical benefit and driven by evidence. There is currently little evidence to guide treatment in each specific phenotype/endotype, thus the requirement for further categorization is questionable, no matter how well intentioned. ${ }^{1,18}$ Based on the existing definition, patients with ACOS may experience different characteristics to different degrees along the spectrum of those featured in the definitions of asthma and COPD. For instance, a patient with a history of asthma since childhood who developed fixed airflow obstruction after a significant smoking habit most likely differs significantly from a patient with a long-standing diagnosis of COPD and no history of asthma who presents with some "asthmatic" characteristics in elderly age (eg, eosinophilic airway inflammation and/or significant reversibility of airflow limitation). This additional subcategorization and definitions may lead to clinical confusion and inappropriate simplification and resource use and should be carefully considered.

\section{What do we know about the mechanisms underlying ACOS?}

For many years, physicians have been aware that asthma and COPD can coexist in some patients and have been treating those patients accordingly. ${ }^{19}$ However, despite the widespread recognition of some overlap between the two diseases, the mechanisms underlying the overlap between asthma and COPD remain controversial. Two long-standing hypotheses have been proposed in an attempt to highlight the underlying disease mechanisms: the "Dutch hypothesis" proposes that asthma and COPD are manifestations of the same basic disease process, with the former predisposing to the latter during the aging process, ${ }^{20}$ whereas the "British hypothesis" suggests that asthma and COPD are distinct entities generated by different mechanisms. ${ }^{21}$ In this hypothesis, it is thought that, in patients with characteristics of both asthma and COPD, both diseases coexist separately in the same individual. Some recent analyses support both hypotheses. ${ }^{22}$

The complex pathophysiological mechanisms and associated triggers underlying asthma and COPD are well studied and reviewed elsewhere. ${ }^{23,24}$ In patients with asthma, the "typical" pathogenic processes are known to include mast cell-mediated bronchoconstriction, inflammation due to local antibody production, and eosinophilic inflammation. These complex processes are mediated by a number of different messenger molecules, including histamine, cysteinyl leukotrienes, prostaglandin $\mathrm{D}_{2}$, interleukins (ILs), and chemokines (Figure 2). ${ }^{25-28}$ The airflow limitation experienced in a majority of patients with asthma is usually reversible; a diagnosis of persistent airflow limitation is usually only characteristic of patients with severe asthma. ${ }^{1,29}$ In patients with COPD, the typical pathogenic mechanisms include mucus hypersecretion, alveolar wall destruction, and fibrosis. Again, these complex processes are orchestrated by various cells and messenger molecules, including epithelial cells, macrophages, chemokines, monocytes, neutrophils, T-helper cells, and type 1 cytotoxic cells. ${ }^{25-27}$ Airflow limitation in patients with COPD is not generally reversible by short-acting $\beta_{2}$-agonists alone. ${ }^{1}$ In patients with overlap between asthma and COPD, the extent of the contribution of the underlying mechanisms of the two diseases may differ significantly between individuals, driven mainly by genetic predisposition, environmental exposure, the initiating condition, and the evolution of the natural history of each patient.

In both asthma and COPD, the pathogenic processes are triggered by interactions between host and environmental factors; the same assumption is made in patients experiencing overlapping asthma and COPD (Figure 2). ${ }^{30}$ In addition to the multiple risk factors shown in Figure 2, evidence suggests that asthma is an independent risk factor for COPD. ${ }^{11,13,31-33}$ For example, a longitudinal, prospective study of children aged 6-7 years, followed to age 50 years, showed that children with asthma were at considerably greater risk of developing COPD than children without asthma. ${ }^{32}$ Furthermore, the Tucson cohort study observed that asthmatic subjects were 12.5 times more likely to develop COPD than healthy individuals. ${ }^{33}$ Finally, the Behavioral Risk Factor Surveillance System Asthma Call-back Survey showed that, in patients with active asthma, the prevalence of physician-diagnosed COPD was higher than in patients with inactive asthma, ${ }^{11}$ with the potential bias this approach may incorporate. It is likely that some patients with asthma may complicate with COPD, typically following long-standing exposure to cigarette smoke or other environmental noxious particles of gases. ${ }^{13,31}$

There are conflicting data regarding the genetic component underlying overlapping asthma and COPD. Some analyses have suggested no common genetic component, 


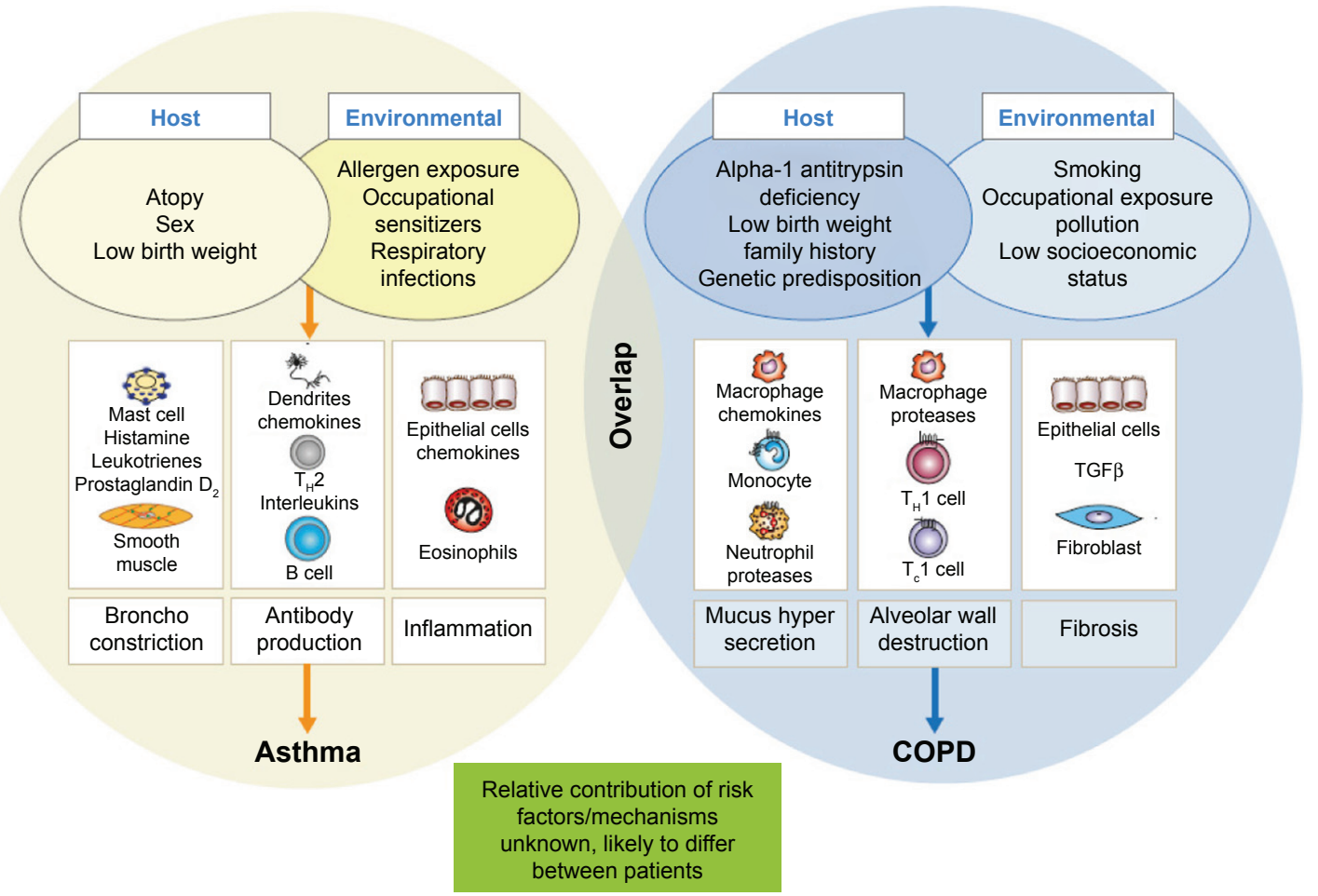

Figure 2 Pathophysiology of asthma, COPD, and overlap.

Notes: Data taken from Postma et $\mathrm{a}^{25}$ and Barnes et al. ${ }^{27}$

Abbreviations: TGF $\beta$, tumor growth factor $\beta$; $T_{H}$ I, T-helper I; $T_{C} I$, type I cytotoxic $T$ cells.

while others have identified several variants associated with the overlap of COPD and asthma that approach genome-wide significance and may be of relevance; further work in this area is needed. ${ }^{34,35}$

\section{Clinical and imaging characteristics}

In order for a definition of ACOS to be clinically useful, consistency of clinical features that are distinct from asthma and COPD should be apparent. However, it is obvious to experienced clinicians that a patient with childhood asthma who has smoked for several years and has subsequently developed persistent airflow obstruction would significantly differ from a long-standing smoker with no history of airway disease in childhood who developed a syndrome with overlapping characteristics of asthma and COPD in middle age, even though both these patients may present characteristics that would allow for their inclusion under the ACOS umbrella term. Several large studies have assessed the clinical features of patients with overlapping asthma and COPD, including COPDGene (COPD genetic epidemiology) and PLATINO (COPD in five Latin American cities: a prevalence study). ${ }^{34,36}$ In COPDGene, which was designed to identify genetic factors associated with COPD, patients with overlapping asthma and COPD were younger, more likely to be African-American, smoked less, had greater airway wall thickness, and more gas trapping on expiratory chest CT scans than subjects with COPD alone. In addition, patients with overlapping asthma and COPD experienced more exacerbations and worse quality of life compared with patients with COPD, despite similar lung function. ${ }^{34}$ Similarly, in PLATINO, a Latin American project for the investigation of airways obstruction, a higher risk of exacerbations was observed in patients with both asthma and COPD compared with COPD alone. ${ }^{36}$ The PLATINO study also showed that, as could be anticipated by the presence of two respiratory diseases rather than one, patients with overlapping asthma and COPD experience a higher risk of hospitalization, more respiratory symptoms, worse lung function, and generally worse health status compared with patients with COPD alone. ${ }^{36}$ It is widely recognized today that patients with COPD and coexisting asthma present with a higher disease burden, despite any possible conceptual expectation that the reversible or treatable component of asthma would allow for more effective management and better outcomes.

Airway remodeling occurs in both asthma and COPD. While there are structural similarities in terms of the remodeling between the diseases, the magnitude of change is known to differ. Few studies have accurately assessed the structural changes in patients with overlapping asthma and COPD 
compared with asthma and COPD alone. Increased airway wall thickness, measured using CT scans, is considered a surrogate measure of airway remodeling and has been observed in patients with overlapping asthma and COPD compared with patients with normal lung function. ${ }^{37}$ In patients with asthma, increased wall thickness has largely been attributed to inflammation, subepithelial fibrosis, and increased thickness of the smooth muscle. ${ }^{13,36,38,39}$ Wall thickening is present, but less obvious, in patients with COPD compared with asthma, and the same structural components (epithelium, reticular basement membrane, airway smooth muscle, and mucous glands) are implicated. ${ }^{13}$ Goblet cell hyperplasia is a feature of the remodeled airway in both patients with asthma and those with COPD. ${ }^{13}$ Similarly, increased airway wall fibrosis is reported in patients with both asthma and COPD. ${ }^{13}$ Despite the wide array of features that may be present in patients with coexisting or overlapping asthma and COPD, no specific imaging characteristics of ACOS have been identified to date, probably due to the heterogeneity of this population.

\section{Biomarkers in identification and management}

The identification of a biomarker or a panel of inflammatory biomarkers that allows a more precise etiologic diagnosis between asthma and COPD and overlap between the two (if appropriate) would be plausibly the most effective approach for patient classification and tailored treatment. ${ }^{40,41}$ The GOLD 2015 COPD guidelines provide some guidance in terms of biomarkers for patients with asthma and COPD (Table 1), but little is known about patients with overlap between the two diseases. ${ }^{14}$ In a small study of 44 patients with stable airways disease, sputum neutrophils and total cells were highest in patients with overlapping COPD and asthma and COPD alone compared to those with asthma alone and healthy controls, whereas eosinophil numbers were significantly increased in patients with asthma compared with controls, but not different between asthma and COPD or patients with overlapping asthma and COPD. ${ }^{13}$ In general, the presence of eosinophilic airways inflammation may be a predictor of steroid responsiveness in patients with asthma, whereas more limited data support this approach in patients with COPD or ACOS. ${ }^{42,43}$ There is some evidence that eosinophilic airway inflammation is an indicator of potential benefit of inhaled corticosteroid (ICS) therapy, whereas the absence of eosinophilic inflammation may be an indication for nonICS containing treatment regimens, but further prospective studies in this area are required. ${ }^{44-46}$

The following studies have attempted to include biomarker analyses as diagnostic tools in order to assess the prevalence of overlapping asthma and COPD in patients with respiratory disease. A descriptive study by Tamada et $\mathrm{al}^{40}$ used fractional exhaled nitric oxide (FeNO; 35 ppb cutoff value) as the diagnostic standard of ACOS in a population of patients with COPD, revealing a prevalence of $16 \%$. However, some caution is required in the interpretation of these results, although FeNO has been shown to be a diagnostic biomarker in patients with asthma, data in patients with COPD are less consistent, possibly due to the confounding influence of smoking. ${ }^{47-49}$ The biomarker profiles of patients with asthma, COPD and overlapping asthma and COPD were assessed in a study by Iwamoto et al. ${ }^{50}$ The authors found that patients with overlapping asthma and COPD and COPD alone had a similar biomarker profile in plasma surfactant protein A, the soluble form of receptor for advanced glycation of end-products, and sputum myeloperoxidase levels, which differed from the profile in patients with asthma. In addition, elevated levels of sputum neutrophil gelatinase-associated lipocalin were observed in patients with overlapping asthma and COPD versus COPD alone, highlighting potential differences in the underlying mechanisms of these diseases and representing a finding that may warrant further study. ${ }^{50}$

A study by Ghebre et $\mathrm{al}^{22}$ used sputum cytokine profiling to determine the existence of distinct and overlapping

Table I Inflammatory biomarkers in the diagnosis of asthma and COPD

\begin{tabular}{lll}
\hline & Asthma & COPD \\
\hline Test for atopy (specific lgE and/or skin prick tests) & $\begin{array}{l}\text { Modestly increases probability of asthma; not } \\
\text { relevant in nonatopic asthma } \\
\text { FeNO }\end{array}$ & $\begin{array}{l}\text { A high level }(>50 \mathrm{ppb}) \text { in non-smokers supports a } \\
\text { diagnosis of eosinophilic airway inflammation }\end{array}$ \\
& Lower in smoking asthmatics \\
Blood eosinophilia & Supports asthma diagnosis \\
Sputum inflammatory cell analysis & Role in differential diagnosis is not established in large \\
& populations
\end{tabular}

Note: Reproduced after permission from the Global Strategy for Diagnosis, Management and Prevention of COPD 2016 @. ${ }^{15}$

Abbreviations: FeNO, fractional exhaled nitric oxide; IgE, immunoglobulin $\mathrm{E}$. 
groups of patients with COPD and/or asthma (as defined by the GINA/GOLD guidelines). Three main clusters were identified: Cluster 1 was asthma predominant with evidence of eosinophilic inflammation and increased type 2 T-helper (Th-2) inflammatory mediators; Cluster 2 contained an asthma and COPD overlap group, with predominately neutrophilic airway inflammation and elevated levels of IL- $1 \beta$ and tumor necrosis factor- $\alpha$ and increased bacterial colonization; Cluster 3 was a COPD predominant group with mixed granulocytic airway inflammation and high sputum IL-6 and chemokine ligand 13 levels, and eosinophilic inflammation in some subjects. ${ }^{22}$ Despite potential implications for stratified management targeting inflammatory pathways, the results of this small study require confirmation in future studies.

\section{Diagnostic approach}

The heterogeneous nature of the multiple entities included under the ACOS umbrella makes diagnosis challenging; ${ }^{51}$ a number of diagnostic approaches have been suggested. The GINA/GOLD documents recommend a stepwise approach, comprising recognition of the presence of a chronic airways disease, syndromic categorization as asthma, COPD or ACOS, confirmation by spirometry and, if necessary, referral for specialized investigations. Although initial recognition and treatment of overlapping asthma and COPD may be made in primary care, referral for confirmatory investigations is encouraged, as outcomes for patients with overlapping disease are often worse than for either disease alone. ${ }^{1}$ The Australian Asthma Management Handbook recommends pooling features corresponding to asthma and COPD in order to make a diagnosis. ${ }^{52}$ The Japanese Respiratory Society's COPD guidelines suggest the following indices for the diagnosis of an asthma component: paroxysmal dyspnea, cough, and wheeze that is worse at night and in the early morning, atopy, and the presence of peripheral blood and/or sputum eosinophilia. ${ }^{53}$ The Spanish COPD consensus document for asthma-COPD overlap proposes three major and three minor criteria required for a diagnosis (Table 2), suggesting that two major criteria or one major and two or more minor criteria are strongly indicative of overlapping asthma and COPD. ${ }^{7}$ The Czech guidelines are very similar to the Spanish guidelines. ${ }^{54}$ The differences in diagnostic approaches between guidelines highlight the complexities involved in attempts to further subclassify respiratory disease. It is important to stress that the majority of the aforementioned guidelines and position papers focus on the identification of an asthmatic component in patients with diagnosed COPD, as this is plausibly the most relevant approach for the effective management of individual patients.
Table 2 Major and minor criteria for the identification of the mixed COPD/asthma phenotype

\begin{tabular}{|c|c|}
\hline Major criteria $^{a}$ & Minor criteria $^{a}$ \\
\hline $\begin{array}{l}\text { Very positive bronchodilator } \\
\text { test (increase of } F E V_{1} \geq 15 \% \\
\text { and } \geq 400 \mathrm{~mL} \text { over baseline) }\end{array}$ & High tota \\
\hline Eosinophilia in sputum & Personal history of atopy \\
\hline $\begin{array}{l}\text { Personal history of asthma } \\
\text { (before the age of } 40 \text { years) }\end{array}$ & $\begin{array}{l}\text { Positive bronchodilator test (increase } \\
\text { in } \mathrm{FEV}_{1} \geq 12 \% \text { and } \geq 200 \mathrm{~mL} \text { over } \\
\text { baseline) on two or more occasions }\end{array}$ \\
\hline \multicolumn{2}{|c|}{ 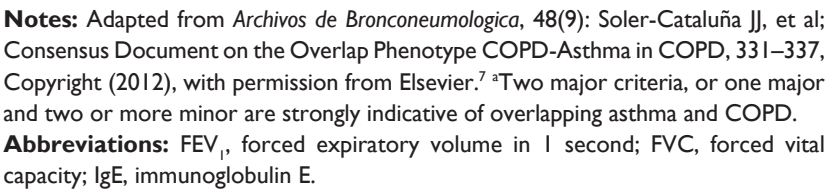 } \\
\hline
\end{tabular}

\section{Principles of management}

Potential treatment options (pharmacological and nonpharmacological) are listed in Table 3; it should be noted that none of the treatments stated in Table 3 are specific for the management of patients with overlap of asthma and COPD, and they are all indicated for the management of one or both conditions. The first step in the management of any patient with characteristics of both asthma and COPD is to provide advice on minimizing exposure to risk factors, such as smoking and allergens. The evidence base for the pharmacological treatment of patients with overlap between asthma and COPD is weak, as such patients have historically been excluded from randomized treatment trials; recommendations for management are therefore extrapolated from trials of either disease alone and are opinion led. ${ }^{13}$ Despite this, there is a common opinion among specialists that patients with characteristics of overlapping asthma and COPD should be considered and treated differently from those with COPD. ${ }^{55,56}$

The management of patients with overlapping COPD and asthma requires the aggressive treatment of both conditions, including optimal bronchodilation and the appropriate dose of ICS, adjusted for disease severity. Most consensus papers recommend the use of long-acting beta agonist (LABA)/ ICS combination therapy in these patients. In addition, the use of "triple" therapy (long-acting muscarinic antagonist [LAMA], LABA, and ICS) may be considered as an appropriate option in patients with more severe symptoms, especially in the presence of frequent exacerbations. ${ }^{55}$ It is, however, important to consider that some patients may present reduced response to ICS, especially patients with COPD who continue to smoke or those who smoke and have asthma. ${ }^{57,58}$ Some evidence suggests that, in asthmatic smokers, leukotriene modifiers and low-dose theophylline may be of benefit; ${ }^{58,59}$ however, it should be noted that these data were not obtained in patients with overlapping asthma 
Table 3 Potential pharmacological and nonpharmacological treatment options in patients with asthma-COPD overlap

\begin{tabular}{|c|c|}
\hline & Comments \\
\hline \multicolumn{2}{|l|}{ Pharmacological } \\
\hline ICS & $\begin{array}{l}\text { Limited supporting evidence; recommended in opinion-led guidelines, } \\
\text { as required; ICS monotherapy is not indicated in patients with COPD }\end{array}$ \\
\hline Long-acting bronchodilators (LABA and/or LAMA) & $\begin{array}{l}\text { Limited supporting evidence; recommended in opinion-led guidelines, } \\
\text { as required; LABA monotherapy is not indicated in patients with asthma }\end{array}$ \\
\hline ICS/LABA & $\begin{array}{l}\text { Limited supporting evidence; recommended in opinion-led guidelines, } \\
\text { as required }\end{array}$ \\
\hline ICS/LABA/LAMA & $\begin{array}{l}\text { Limited supporting evidence; recommended in opinion-led guidelines, } \\
\text { as required }\end{array}$ \\
\hline Other (eg, biologicals, theophylline, LTRA, phosphodiesterase & Very limited data in patients with overlapping asthma and COPD; some \\
\hline 4 inhibitors, macrolides; anti-leukotrienes, MABA, p38 MAPK & are still in development; none are approved in opinion-led guidelines \\
\hline \multicolumn{2}{|l|}{ inhibitors; 5-lipoxygenase inhibitor) } \\
\hline Vaccination & Recommended in opinion-led guidelines \\
\hline \multicolumn{2}{|l|}{ Nonpharmacological } \\
\hline Smoking cessation advice and treatment & Recommended in opinion-led guidelines \\
\hline Pulmonary rehabilitation & $\begin{array}{l}\text { Recommended in opinion-led guidelines, as required; effective in } \\
\text { patients with COPD }\end{array}$ \\
\hline Bronchial thermoplasty & $\begin{array}{l}\text { No known evidence available in patients with overlapping asthma and } \\
\text { COPD }\end{array}$ \\
\hline Treatment of comorbidities & $\begin{array}{l}\text { Recommended in opinion-led guidelines, although limited evidence } \\
\text { available regarding the impact of comorbidities on disease outcomes } \\
\text { and treatment choice }\end{array}$ \\
\hline
\end{tabular}

Note: Data taken from Louie et al. ${ }^{69}$

Abbreviations: ICS, inhaled corticosteroid; LABA, long-acting beta agonist; LAMA, long-acting muscarinic antagonist; LTRA, leukotriene receptor antagonists; MABA, dual pharmacophore with long-acting muscarinic antagonist and $\beta 2$ agonist pharmacology; MAPK, mitogen-activated protein kinase.

and COPD. Individuals receiving LABA/ICS, but still with poorly controlled asthma, have been shown to benefit from the addition of a LAMA (such as tiotropium) ${ }^{60}$ although the same would seem intuitive in patients with overlapping asthma and COPD, there is currently no evidence to support this hypothesis. ${ }^{60}$

As with the selection of any therapy regimen, potential safety and tolerability issues warrant careful consideration. For example, long-term ICS use has been associated with an increased risk of side effects in patients with COPD,${ }^{61}$ but it is not known whether the risk in patients with overlapping asthma and COPD is the same. ${ }^{1,61}$ In patients with asthma, omitting ICS therapy and treating with LABA monotherapy is associated with deteriorating asthma control, increased severity, and increased mortality. ${ }^{62}$ Although the impact of LABA monotherapy in patients with overlapping asthma and COPD is not known, a cautious approach to monotherapy in these patients may be warranted due to the known increased burden of disease in these patients. ${ }^{62}$

Although there is, on average, a higher rate of exacerbations in patients with COPD and asthma versus COPD alone, a significant number of patients with COPD also experience frequent exacerbations without the presence of an asthmatic component. It is important to clearly differentiate exacerbating patients with COPD and no asthmatic component, because these patients may benefit more from dual bronchodilation prior to the use of ICS or any other anti-inflammatory therapy. ${ }^{63,64}$ The efficacy of triple therapy (LABA/LAMA/ICS) in the reduction of exacerbations may have benefits, compared with LABA/LAMA in exacerbating patients with COPD; however, there is a need for prospective clinical trials in this specific population to explore this further. ${ }^{65}$ Other anti-inflammatory options in exacerbating patients with COPD on effective inhaled therapies include phosphodiesterase- 4 inhibitors and macrolides. The results of the Roflumilast and Exacerbations in patients receiving Appropriate Combination Therapy (REACT) study provide some evidence that, in patients with severe COPD with symptoms of chronic bronchitis and at least two exacerbations in the previous year, treatment with roflumilast may reduce exacerbations and hospital admissions, on top of ICS and LABA therapy compared with placebo. ${ }^{66}$ However, studies comparing this combination to LABA/LAMA/ICS treatment are not available, so it is not clear which combinations are more efficacious. Finally, in patients with COPD with an increased risk of exacerbations, the addition of macrolides to usual treatment has been associated with decreased frequency of exacerbations compared with placebo, although side effects and potential increase in resistance to macrolides should be always considered. ${ }^{67,68}$

It is clear that, although there is substantial evidence to guide treatment in the majority of patients with asthma 
and COPD as separate diseases, more research is needed on the effects of different treatments in patients with overlap between the two diseases. The most important first step in the management of such patients is the identification of the predominant disorder that would determine the basis of the appropriate treatment. As with all patients with airways disease, patients with overlapping asthma and COPD, especially those with frequent exacerbations, should be carefully monitored and encouraged to report any deterioration (eg, worsening of cough, wheezing, and dyspnea) following the initiation or change of treatment. ${ }^{69}$

\section{Challenging the concept of ACOS and a proposed algorithmic approach}

The management of the majority of patients with "pure" COPD or asthma may not present major challenges, as these patients may be successfully treated with established strategies, which work to optimize bronchodilator or antiinflammatory therapy, respectively. In some patients with more severe or difficult-to-treat forms of either disease, experienced clinicians have little difficulty in incorporating additional treatment options based on specific characteristics, which permit classification into different phenotypes or endotypes. The introduction of an additional collective term with unclear characteristics and nonspecific guidance like ACOS may result in confusion and difficulty in the selection of appropriate treatment options by the busy primary care physician. We strongly believe that the identification of the predominant diagnosis and the potential underlying inflammatory pattern remains central to the proper management of all patients with airways disease. A potential four-step algorithmic approach for patients with overlapping clinical characteristics of asthma and COPD may include the steps outlined in Figure 3. In this approach, the second step after the identification of patients with airway disease would be the evaluation of eosinophilic airways inflammation (eg, by increased sputum eosinophils or FeNO) or other asthma characteristics (eg, very positive bronchodilator reversibility), which may represent an indication for ICS use and dose optimization. The presence of persistent airflow obstruction (as expressed by the absence of complete reversibility after bronchodilator reversibility testing and/or treatment) may represent an indication for optimization (or maximization) of bronchodilation in appropriate patients (ie, via combination therapy of LAMA and LABA). Finally, the thorough evaluation of exacerbation history can lead to the selection of the most appropriate treatment for exacerbation reduction,

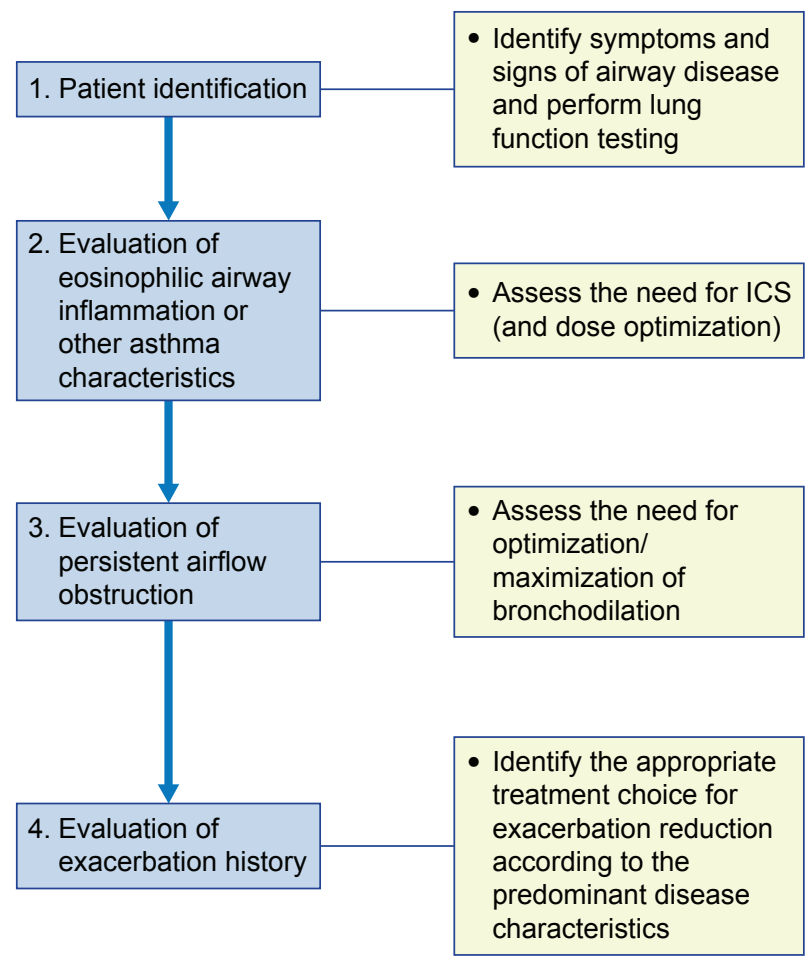

Figure 3 Proposed algorithmic approach for patients with overlapping clinical characteristics of asthma and COPD.

Abbreviation: ICS, inhaled corticosteroid.

according to the predominant disease characteristics, as described in the principles of management section.

\section{Conclusion and the potential future of ACOS}

The term ACOS represents a recent "revival" of the longstanding concept of overlap between the two most common airways diseases, COPD and asthma, in some patients. Despite the best of intentions, the complexities of terms such as ACOS are apparent, since the absence of a clear definition and the inclusion of patients with different characteristics under this umbrella term may not facilitate treatment decisions, especially in the absence of clinical trials addressing this heterogenic population.

It is our opinion that a more clinically relevant approach would be to raise awareness of the heterogeneity that exists within current definitions of respiratory disease to facilitate optimal, timely, and individualized treatment for our patients.

\section{Acknowledgments}

The authors were assisted in the preparation of the manuscript by Rebecca Douglas, $\mathrm{PhD}$, a professional medical writer contracted to CircleScience, an Ashfield Company, part of UDG 
Healthcare plc (Tytherington, UK). Medical writing support was funded by Novartis Pharma AG (Basel, Switzerland).

\section{Disclosure}

KK has been an employee and shareholder of Novartis Pharma AG since January 1, 2015. In the previous 5 years, he had received honoraria for educational activities and lectures from AstraZeneca, Boehringer Ingelheim, Chiesi, ELPEN, GSK, MSD, Novartis, Takeda, and UCB and has served on advisory boards arranged by AstraZeneca, Chiesi, ELPEN, Novartis, and Takeda. AC and FP are employees and shareholders of Novartis Pharma AG. The authors report no other conflicts of interest in this work.

\section{References}

1. Global Initiative for Asthma (GINA); Global Initiative for Chronic Obstructive Lung Disease (GOLD) [webpage on the Internet]. Diagnosis of diseases of chronic airflow limitation: asthma COPD and asthma - COPD Overlap Syndrome (ACOS). Updated 2015; 2015. Available from: http://goldcopd.org/asthma-copd-asthma-copdoverlap-syndrome/. Accessed February 5, 2016.

2. Miravitlles M, Soler-Cataluña JJ, Calle M, Soriano JB. Treatment of COPD by clinical phenotypes: putting old evidence into clinical practice. Eur Respir J. 2013;41(6):1252-1256.

3. Milne S, King GG. Role of imaging in COPD phenotyping. Respirology. 2015;20(4):522-523

4. Hardin M, Silverman EK, Barr RG, et al; COPDGene Investigators. The clinical features of the overlap between COPD and asthma. Respir Res. 2011;12:127.

5. Kauppi $\mathrm{P}$, Kupiainen H, Lindqvist A, et al. Overlap syndrome of asthma and COPD predicts low quality of life. J Asthma. 2011;48(3): 279-285.

6. Gerhardsson de Verdier M, Andersson M, Kern DM, Zhou S, Tunceli O. Asthma and chronic obstructive pulmonary disease overlap syndrome: doubled costs compared with patients with asthma alone. Value Health. 2015;18(6):759-766.

7. Soler-Cataluña JJ, Cosío B, Izquierdo JL, et al. Consensus document on the overlap phenotype COPD-asthma in COPD. Arch Bronconeumol. 2012;48(9):331-337.

8. de Marco R, Pesce G, Marcon A, et al. The coexistence of asthma and chronic obstructive pulmonary disease (COPD): prevalence and risk factors in young, middle-aged and elderly people from the general population. PLoS One. 2013;8(5):e62985.

9. Wurst KE, Kelly-Reif K, Bushnell GA, Pascoe S, Barnes N. Understanding asthma-chronic obstructive pulmonary disease overlap syndrome. Respir Med. 2016;110:1-11.

10. Gibson PG, McDonald VM. Asthma-COPD overlap 2015: now we are six. Thorax. 2015;70(7):683-691.

11. Mirabelli MC, Beavers SF, Chatterjee AB. Active asthma and the prevalence of physician-diagnosed COPD. Lung. 2014;192(5):693-700.

12. Soriano JB, Davis KJ, Coleman B, Visick G, Mannino D, Pride NB. The proportional Venn diagram of obstructive lung disease: two approximations from the United States and the United Kingdom. Chest. 2003; 124(2):474-481.

13. Gibson PG, Simpson JL. The overlap syndrome of asthma and COPD: what are its features and how important is it? Thorax. 2009;64(8): 728-735.

14. Global Initiative for Asthma (GINA) [webpage on the Internet]. Global strategy for asthma management and prevention. Updated 2015. Available from: http://ginasthma.org/2016-gina-report-global-strategyfor-asthma-management-and-prevention/. Accessed February 5, 2016.
15. Global Initiative for Chronic Obstructive Lung Disease (GOLD) [webpage on the Internet]. Global strategy for the diagnosis, management, and prevention of chronic obstructive pulmonary disease. Updated 2016; 2016. Available from: http://goldcopd.org/global-strategydiagnosis-management-prevention-copd-2016/. Accessed February 5, 2016.

16. Fabbri LM, Romagnoli M, Corbetta L, et al. Differences in airway inflammation in patients with fixed airflow obstruction due to asthma or chronic obstructive pulmonary disease. Am J Respir Crit Care Med.2003; 167(3):418-424.

17. Tashkin DP, Celli B, Decramer M, et al. Bronchodilator responsiveness in patients with COPD. Eur Respir J. 2008;31(4):742-750.

18. Weatherall M, Travers J, Shirtcliffe PM, et al. Distinct clinical phenotypes of airways disease defined by cluster analysis. Eur Respir J. 2009; 34(4):812-818.

19. Lange P, Parner J, Vestbo J, Schnohr P, Jensen G. A 15-year follow-up study of ventilatory function in adults with asthma. NEngl J Med. 1998; 339(17):1194-1200.

20. Orie NGM, Sluiter HJ, de Vries K, Tammeling GJ, Witkop J. The host factor in bronchitis. In: Orie NGM, Sluiter HJ, editors. Bronchitis. Assen, The Netherlands: Royal Van Gorcum; 1961:43-59.

21. Barnes PJ. Against the Dutch hypothesis: asthma and chronic obstructive pulmonary disease are distinct diseases. Am J Respir Crit Care Med.2006; 174(3):240-243. [discussion 3-4].

22. Ghebre MA, Bafadhel M, Desai D, et al. Biological clustering supports both "Dutch" and "British" hypotheses of asthma and chronic obstructive pulmonary disease. J Allergy Clin Immunol. 2015;135(1):63-72.

23. National Heart Lung and Blood Institute (NHLBI); National Institutes of Health (NIH) [webpage on the Internet]. Expert panel report 3: guidelines for the diagnosis and management of asthma. Full report. Washington, DC: US Department of Health and Human Services; 2007. Available from: http://www.nhlbi.nih.gov/guidelines/asthma/asthgdln htm. Accessed January 13, 2014.

24. Tuder RM, Petrache I. Pathogenesis of chronic obstructive pulmonary disease. J Clin Invest. 2012;122(8):2749-2755.

25. Postma DS, Rabe KF. The asthma-COPD overlap syndrome. $N$ Engl J Med. 2015;373(13):1241-1249.

26. Sutherland ER, Martin RJ. Airway inflammation in chronic obstructive pulmonary disease: comparisons with asthma. J Allergy Clin Immunol. 2003;112(5):819-827. [quiz 28].

27. Barnes PJ. Immunology of asthma and chronic obstructive pulmonary disease. Nat Rev Immunol. 2008;8(3):183-192.

28. Montuschi P. Leukotrienes, antileukotrienes and asthma. Mini Rev Med Chem. 2008;8(7):647-656.

29. Konstantellou E, Papaioannou AI, Loukides S, et al. Persistent airflow obstruction in patients with asthma: characteristics of a distinct clinical phenotype. Respir Med. 2015;109(11):1404-1409.

30. Alshabanat A, Zafari Z, Albanyan O, Dairi M, FitzGerald JM. Asthma and COPD overlap syndrome (ACOS): a systematic review and meta analysis. PLoS One. 2015;10(9): 0136065.

31. de Marco R, Marcon A, Rossi A, et al. Asthma, COPD and overlap syndrome: a longitudinal study in young European adults. Eur Respir J. 2015;46(3):671-679.

32. Tai A, Tran H, Roberts M, Clarke N, Wilson J, Robertson CF. The association between childhood asthma and adult chronic obstructive pulmonary disease. Thorax. 2014;69(9):805-810.

33. Silva GE, Sherrill DL, Guerra S, Barbee RA. Asthma as a risk factor for COPD in a longitudinal study. Chest. 2004;126(1):59-65.

34. Hardin M, Cho M, McDonald ML, et al. The clinical and genetic features of COPD-asthma overlap syndrome. Eur Respir J. 2014;44(2): 341-350.

35. Smolonska J, Koppelman GH, Wijmenga C, et al. Common genes underlying asthma and COPD? Genome-wide analysis on the Dutch hypothesis. Eur Respir J. 2014;44(4):860-872.

36. Menezes AM, Montes de Oca M, Pérez-Padilla R, et al. Increased risk of exacerbation and hospitalization in subjects with an overlap phenotype: COPD-asthma. Chest. 2014;145(2):297-304. 
37. Bumbacea D, Campbell D, Nguyen L, et al. Parameters associated with persistent airflow obstruction in chronic severe asthma. Eur Respir J. 2004; 24(1):122-128.

38. Ward C, Pais M, Bish R, et al. Airway inflammation, basement membrane thickening and bronchial hyperresponsiveness in asthma. Thorax. 2002;57(4):309-316.

39. Montuschi P, Barnes PJ. New perspectives in pharmacological treatment of mild persistent asthma. Drug Discov Today. 2011;16(23-24): 1084-1091.

40. Tamada T, Sugiura H, Takahashi T, et al. Biomarker-based detection of asthma-COPD overlap syndrome in COPD populations. Int J Chron Obstruct Pulmon Dis. 2015;10:2169-2176.

41. Malerba M, Montuschi P. Non-invasive biomarkers of lung inflammation in smoking subjects. Curr Med Chem. 2012;19(2):187-196.

42. Smith AD, Cowan JO, Brassett KP, et al. Exhaled nitric oxide: a predictor of steroid response. Am J Respir Crit Care Med. 2005;172(4): 453-459.

43. Brightling CE, McKenna S, Hargadon B, et al. Sputum eosinophilia and the short term response to inhaled mometasone in chronic obstructive pulmonary disease. Thorax. 2005;60(3):193-198.

44. Pavord ID, Shaw DE, Gibson PG, Taylor DR. Inflammometry to assess airway diseases. Lancet. 2008;372(9643):1017-1019.

45. Pascoe S, Locantore N, Dransfield MT, Barnes NC, Pavord ID. Blood eosinophil counts, exacerbations, and response to the addition of inhaled fluticasone furoate to vilanterol in patients with chronic obstructive pulmonary disease: a secondary analysis of data from two parallel randomised controlled trials. Lancet Respir Med. 2015;3(6):435-442.

46. Pavord ID, Lettis S, Locantore N, et al. Blood eosinophils and inhaled corticosteroid/long-acting beta-2 agonist efficacy in COPD. Thorax. 2016;71(2):118-125.

47. Kostikas K, Minas M, Papaioannou AI, Papiris S, Dweik RA. Exhaled nitric oxide in asthma in adults: the end is the beginning? Curr Med Chem. 2011;18(10):1423-1431.

48. Koutsokera A, Kostikas K, Nicod LP, Fitting JW. Pulmonary biomarkers in COPD exacerbations: a systematic review. Respir Res. 2013;14:111.

49. Santini G, Mores N, Shohreh R, et al. Exhaled and non-exhaled noninvasive markers for assessment of respiratory inflammation in patients with stable COPD and healthy smokers. J Breath Res. 2016;10(1): 017102.

50. Iwamoto H, Gao J, Koskela J, et al. Differences in plasma and sputum biomarkers between COPD and COPD-asthma overlap. Eur Respir J. 2014;43(2):421-429.

51. McDonald VM, Simpson JL, Higgins I, Gibson PG. Multidimensional assessment of older people with asthma and COPD: clinical management and health status. Age Ageing. 2011;40(1):42-49.

52. National Asthma Council (Australia) [webpage on the Internet]. Australian Asthma Management Handbook 2014. Available from: http://www.nationalasthma.org.au/handbook. Accessed February 5, 2016.

53. Committee for the Third Edition of the COPD Guidelines of the Japanese Respiratory Society [webpage on the Internet]. Guidelines for the Diagnosis and Treatment of COPD (Chronic Obstructive Pulmonary Disease). 3rd Edition. Available from: http://www.jrs.or.jp/uploads/ uploads/files/photos/765.pdf2010
54. Koblizek V, Chlumsky J, Zindr V, et al. Chronic Obstructive Pulmonary Disease: official diagnosis and treatment guidelines of the Czech Pneumological and Phthisiological Society; a novel phenotypic approach to COPD with patient-oriented care. Biomed Pap Med Fac Univ Palacky Olomouc Czech Repub. 2013;157(2):189-201.

55. Miravitlles M, Alcazar B, Alvarez FJ, et al. What pulmonologists think about the asthma-COPD overlap syndrome. Int J Chron Obstruct Pulmon Dis. 2015;10:1321-1330.

56. Montuschi P, Malerba M, Santini G, Miravitlles M. Pharmacological treatment of chronic obstructive pulmonary disease: from evidencebased medicine to phenotyping. Drug Discov Today. 2014;19(12): 1928-1935.

57. Martin RJ, Szefler SJ, King TS, et al. The predicting response to inhaled corticosteroid efficacy (PRICE) trial. J Allergy Clin Immunol. 2007; 119(1):73-80.

58. Lazarus SC, Chinchilli VM, Rollings NJ, et al. Smoking affects response to inhaled corticosteroids or leukotriene receptor antagonists in asthma. Am J Respir Crit Care Med. 2007;175(8):783-790.

59. Spears M, Donnelly I, Jolly L, et al. Effect of low-dose theophylline plus beclometasone on lung function in smokers with asthma: a pilot study. Eur Respir J. 2009;33(5):1010-1017.

60. Kerstjens HA, Engel M, Dahl R, et al. Tiotropium in asthma poorly controlled with standard combination therapy. N Engl J Med. 2012; 367(13):1198-1207.

61. Suissa S, Patenaude V, Lapi F, Ernst P. Inhaled corticosteroids in COPD and the risk of serious pneumonia. Thorax. 2013;68(11):1029-1036.

62. Chowdhury BA, Dal Pan G. The FDA and safe use of long-acting beta-agonists in the treatment of asthma. N Engl J Med. 2010;362(13): 1169-1171.

63. Montuschi P, Ciabattoni G. Bronchodilating drugs for chronic obstructive pulmonary disease: current status and future trends. J Med Chem. 2015;58(10):4131-4164.

64. Zhong N, Wang C, Zhou X, et al. LANTERN: a randomized study of QVA149 versus salmeterol/fluticasone combination in patients with COPD. Int J COPD. 2015;10(1):1015-1026.

65. Patalano F, Banerji D, D'Andrea P, Fogel R, Altman P, Colthorpe P. Addressing unmet needs in the treatment of COPD. Eur Respir Rev. 2014; 23(133):333-344.

66. Martinez FJ, Calverley PM, Goehring UM, Brose M, Fabbri LM, Rabe KF. Effect of roflumilast on exacerbations in patients with severe chronic obstructive pulmonary disease uncontrolled by combination therapy (REACT): a multicentre randomised controlled trial. Lancet. 2015;385(9971):857-866.

67. Seemungal TA, Wilkinson TM, Hurst JR, Perera WR, Sapsford RJ, Wedzicha JA. Long-term erythromycin therapy is associated with decreased chronic obstructive pulmonary disease exacerbations. $\mathrm{Am}$ J Respir Crit Care Med. 2008;178(11):1139-1147.

68. Albert RK, Connett J, Bailey WC, et al. Azithromycin for prevention of exacerbations of COPD. N Engl J Med. 2011;365(8):689-698.

69. Louie S, Zeki AA, Schivo M, et al. The asthma-chronic obstructive pulmonary disease overlap syndrome: pharmacotherapeutic considerations. Expert Rev Clin Pharmacol. 2013;6(2):197-219.
International Journal of COPD

\section{Publish your work in this journal}

The International Journal of COPD is an international, peer-reviewed journal of therapeutics and pharmacology focusing on concise rapid reporting of clinical studies and reviews in COPD. Special focus is given to the pathophysiological processes underlying the disease, intervention programs, patient focused education, and self management protocols.

\section{Dovepress}

This journal is indexed on PubMed Central, MedLine and CAS. The manuscript management system is completely online and includes a very quick and fair peer-review system, which is all easy to use. Visit http://www.dovepress.com/testimonials.php to read real quotes from published authors. 